\title{
OS DIÁLOGOS OU AS REFLEXÕES MONOLÓGICAS DA SAUDADE EM MAIS UM DRAMA PORTUGUÊS
}

Milca Tscherne ${ }^{1}$

RESUMO: Luiz Francisco Rebello tematizou a saudade dos tempos anteriores à ditadura salazarista, elegendo a memória como forma de apresentá-la em A Visita de Sua Excelência, drama escrito em 1965. Como o presente absoluto é requisito da forma dramática convencional, ao recordar, os diálogos repercutem mais como reflexões monológicas do que como relação intersubjetiva capazes de desencadear uma ação.

PALAVRAS-CHAVE: Teatro português; Luiz Francisco Rebello; Drama moderno; Dramaturgia; Diálogo dramático.

RESUMÉ: Luiz Francisco Rebello a thématisé la nostalgie des temps avant la dictature de Salazar et il a choisi de la mémoire comme un moyen de présenter A Visita de Sua Excelência, pièce dramatique écrite en 1965. Le présent absolu c'est une exigence du mode classique dramatique, cependant quand la memorie c'est l'objet du dialogue, les conversations se répercutent plus de réflexion monologique que comme relation intersubjective et action dramatique.

MOTS-CLÉS: Théâtre portugais; Luiz Francisco Rebello; Drame moderne; dramaturgie; Dialogue dramatique.

O pós-45 foi um período especialmente curioso para o teatro português. Ainda sob o domínio de uma ditadura, que se iniciara em 1926 e que só iria terminar em 1974, a atividade teatral mostrou-se sensivelmente intensa em Portugal e, mesmo com a censura, peças importantes e ousadas foram não só escritas no país como também levadas ao palco. Almada-Negreiros, Alfredo Cortez, Antônio Botto e José Régio escreveram muitas de suas obras nesse contexto.

$\mathrm{Na}$ busca da atualização teatral portuguesa e na tentativa de aproximar, culturalmente, Portugal da Europa, Luiz Francisco Rebello (n.1924), dramaturgo que especialmente nos interessa aqui, contribuiu, não só com sua extensa obra dramática, mas também com a atividade de pesquisador, historiador e crítico de teatro e tradutor.

Como fundador do Teatro-Estúdio do Salitre, empenhou-se em atualizar o público português. Como dramaturgo, foi um dos renovadores da linguagem cênica do teatro português a partir de 1947.

Seus textos dramáticos apresentam várias peculiaridades e uma delas pode-se perceber de imediato. Rebello costuma introduzir logo na abertura, entre a lista de

\footnotetext{
${ }^{1}$ Doutoranda do Programa de Pós-Graduação da UNESP de Araraquara.
} 


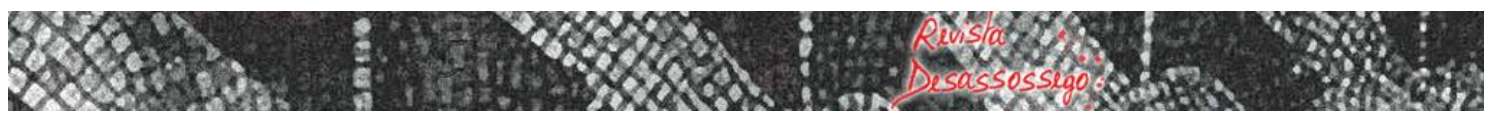

nomes das personagens e as indicações cênicas iniciais, uma espécie de epígrafe que faz referência ao tempo em que as ações se passariam na peça. Em O fim na última página (1951), por exemplo, lê-se: "Hoje, em qualquer cidade". Essas pequenas inscrições contemplam, evidentemente, somente o público leitor e chamam atenção para o contexto de produção do texto.

Em A visita de Sua Excelência - classificada por seu autor como uma "farsa catastrófica" e peça da qual este artigo tratará- a epígrafe anuncia: "A acção desta farsa decorre num dia que há-de vir”. O leitor que atentar para essa antecipação, certamente, depois de lê-la, irá se perguntar: as ações apresentadas são impossíveis no tempo presente? Por quê? Esse dia que há de vir expressa um desejo, uma expectativa ou somente uma chegada inevitável?

É certo que, nesta peça, Rebello elabora formas cênicas para descrever a situação política de Portugal. Mas, para quem desconhece o período português em questão, é praticamente impossível estabelecer textualmente qualquer relação com tal circunstância. A peça é tão isenta de referências contextuais específicas que se poderia tratar de qualquer situação de declínio próxima a uma catástrofe.

Quanto à classificação de farsa, talvez a relação com o gênero se deva ao exagero, aos estereótipos e à paródia do poder que existem em A visita de Sua Excelência ou ainda seria uma referência à acepção que foge às concepções teóricas, mas que também traz um significado legítimo à peça: a farsa como sinônimo de embuste.

\section{A visita de Sua Excelência: o desespero do presente e a saudade do passado}

As personagens de A visita de Sua Excelência são poucas, como prevê a composição farsesca: O Velho, A Velha, O Procurador, dois Guarda-Costas e Sua Excelência.

O espaço é ambientado de maneira miserável: uma mansarda, onde o mobiliário restringe-se a tábuas e caixotes, os quais representam cadeiras, mesa e cama. Nela, o único móvel de verdade é um velho "armário desmantelado, cujas portas se mantêm fechadas por grossas cadeias de ferro" (Rebello, 1999, p. 381). O teto apresenta muitos buracos por onde cai a chuva abundante do período. 


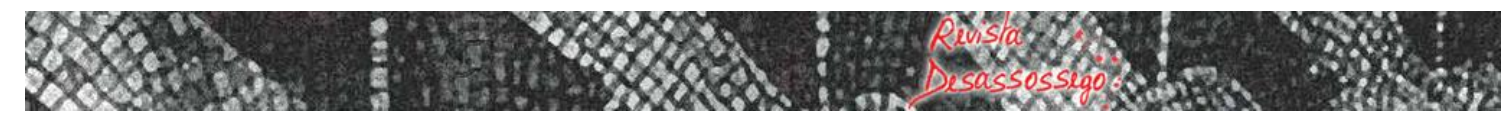

A primeira cena da peça é composta por O Velho e A Velha dentro de sua casa; silenciosos e imóveis, eles protegem-se debaixo de um guarda-chuva. O único barulho que se ouve é o da chuva.

A discussão que se segue ao silêncio inicial é um pouco absurda. A Velha diz que o serviço de telefonia divulgara uma previsão do tempo não condizente com aquela. Depois compara as chuvas com as do mesmo período do ano anterior. Essa observação desencadeia uma discussão sobre a passagem do tempo.

Ambos expressam uma desilusão com as muitas perdas que se avolumaram em suas vidas nos últimos anos:

A VELHA: Dantes só chovia no inverno, lembras-te?

O VELHO (irritado): Lá vens tu outra vez com tuas coisas... Dantes! Que queres dizer com isso? Dantes eu era respeitado, as pessoas tiravam-me o chapéu na rua, tratavam-me por vossa excelência... Na hierarquia social ocupava-me um dos mais altos lugares: (com ênfase) Funcionário público! (REBELLO, 1999, p. 382)

A Velha, diante da atual confusão meteorológica, tem uma ideia que o marido considera absurda: "Porque é que não passamos a chamar Verão de Inverno e Inverno de Verão?” (Rebello, 2001, p.383).

Aborrecido, O Velho diz à sua esposa que ela merecia dormir aquela noite no armário. E como se fossem duas crianças assustadas, ambas as personagens demonstram muito medo do móvel e falam sobre a perda da chave do armário e, novamente, sobre a passagem do tempo.

Neste momento, surge talvez o único indício referencial sobre a ditadura. A peça começou a ser escrita em 1962, data em que o regime militar completava 36 anos em Portugal. Tal referência, no entanto, surge sutilmente dentro da grande alegoria da peça, representada pela casa miserável, que pode, numa das hipóteses de leitura, ser entendida como Portugal agonizante e sem liberdade:

O VELHO - Não digo. Há trinta e seis anos, quando viemos para esta casa, ainda não chovia aqui dentro.

A VELHA - Chovia, mas era só no inverno.

O VELHO - Muito pouco. As telhas ainda não se tinham partido. As janelas tinham vidro. As paredes não tinham fendas.

A VELHA - Foi se gastando tudo, aos poucos, de ano para ano.

O VELHO - E depois de mês para mês...

A VELHA - De semana para semana...

O VELHO - De dia para dia

A VELHA - De hora para hora... 
O VELHO - Agora mesmo...

A VELHA - As minhas tranças...

O VELHO - As minhas crenças...

OS DOIS - As nossas esperanças...

A VELHA - E o armário cada vez mais cheio.

O VELHO (rápido) - Cala-te! - Hoje mesmo, quando o procurador do senhorio vier receber a renda, exijo-lhe que mande tapar esses buracos e que arranje o telhado, que conserte as janelas...

A VELHA - Ora! É o que dizes sempre. (REBELLO, 1999, p. 385)

A Velha lembra que sempre é a mesma história: O Velho promete que vai reclamar das péssimas condições da mansarda, mas nunca reclama. Mas, naquele momento, começa a haver uma mistura dos tempos: a esposa faz o marido recordar-se de que tem uma espada - a de almirante, general e acadêmico, funções acumuladas pelo velho em tempos de outrora. Ela ordena que ele vá buscá-la, mas o velho repete que perdeu a chave do armário.

O casal começa a evocar o passado, quando ambos foram para aquele lugar, como tudo era diferente, como o dono do local os deixava sair e entrar quando queriam, como, nos dias de feriado, O Velho a levava para the mostrar o seu exército, a sua esquadra, os funcionários embalsamados, os colegas da Academia, e como ela se sentia orgulhosa:

A VELHA - Ah, éramos felizes, os dois!

O VELHO - Os quatro.

A VELHA - Os dois.

O VELHO - Os quatro. Ainda eram vivos, então, os nossos filhos.

A VELHA - (de repente, após um silêncio, muito alto) - Dois filhos!

Um rapaz e uma rapariga! Um rapaz que morreu de parto, uma rapariga que morreu pela pátria!

O VELHO - Ao contrário.

A VELHA - Ao contrário? Foi a pátria que morreu por ela?!

O VELHO - A rapariga é que morreu de parto. O rapaz morreu pela pátria.

A VELHA - Mandaram depois o cadáver pelo correio: lembras-te?

O VELHO - Num caixote de madeira que dizia por fora $<<$ Encomenda registrada. Frágil >>

A VELHO - Como se lhes tivéssemos encomendado um filho morto!

O VELHO - No dia seguinte, para compensar, ofereceram-nos, emoldurada, a certidão de óbito do soldado inimigo que matou o nosso filho.

A VELHA - E ao mesmo tempo, em casa dos pais desse ou de outro soldado inimigo, entregavam a certidão de óbito do nosso filho.

O VELHO - Para ficarmos quites - disseram eles. 
A VELHA - Tinham-nos prometido que ganhávamos a guerra. Mas para mim a guerra perdeu-se no momento em que o cadáver do nosso filho entrou por aquela porta...

O VELHO (continuando a frase) - ... e o guardamos naquele armário...

A VELHA - (mesmo jogo) - ... naquele armário cada vez mais cheio.

O VELHO - Ao lado da irmã. (REBELLO, 1999, p. 387)

E as réplicas continuam com os dois velhos elencando tudo o que havia no armário: todas as experiências passadas, tudo o que poderiam ter vivido e tudo o que haviam perdido: os sonhos, as esperanças, o tempo, a vida.

A parte inicial da peça mostra a situação em que o casal se encontra, que é de total penúria, mas é uma parte composta basicamente de rememorações, na qual o dramático ou o mimético cedem lugar ao diegético, à narrativa. Ambos reconstroem o passado, contam sobre os filhos, sobre a boa vida que levavam e sobre como passaram a viver como se fossem prisioneiros:

O VELHO - Perdi todos os meus títulos acadêmicos, oficiais, burocráticos, pirotécnicos, rodoviários, astronáuticos, filosóficos, propedêuticos, pedagógicos, ecumênicos, mediúnicos, arquitectônicos, tectônicos, tónicos e quiromânticos. Eu, que fui tudo, hoje não sou nada!

A VELHA: Porque é que não mudamos de casa?

O VELHO - Eles não deixam. Bem sabes que não deixam. Têm-nos aqui presos, amarrados a estas paredes. (REBELLO, 1999, p. 388)

E a discussão continua com questionamentos sobre o porquê de eles estarem passando por aquilo, se já tinham dado um filho à pátria, se eles pagavam o aluguel, se já tinham dedicado trinta e seis anos de suas vidas a honrar com as obrigações que só aumentavam. A Velha tem a ideia de fugirem e o velho retruca dizendo-lhe que há espiões por toda a parte. A Velha continua a sonhar com a liberdade:

A VELHA - E do armário, sim! Deixávamo-lo ficar aqui. E podíamos começar noutra casa uma vida nova...

O VELHO - Sem termos de arrastar atrás de nós os restos de tudo o que foi morrendo ao longo destes anos... Ah, era bom! (Um breve silêncio, durante o qual ambos perseguem interiormente o mesmo sonho, embora sabendo-o irrealizável. $O$ Velho é o primeiro a reagir.) Mas para que estamos nós a perder tempo com coisas impossíveis! Não tínhamos resolvido de uma vez para sempre enterrar os sonhos no fundo do armário, debaixo das minhas fardas e dos cadáveres dos nossos filhos? (REBELLO, 1999, p. 389) 
Num rompante de coragem, o Velho declara à esposa que, quando lhe vierem cobrar o aluguel, ele reclamará das péssimas condições do imóvel. Diz com uma bela retórica, faz um discurso eloqüente, do alto de um dos caixotes, que faz a Velha aplaudilo com muita admiração. Ambos se empolgam, mas quando o Procurador e os dois guardas chegam, o discurso muda. A Velha cobra a atitude anunciada pelo marido minutos antes. O Velho, acovardando-se, diz ao Procurador que a mulher entende tudo ao contrário. Adiante, para remediar outra situação, diz que ela é surda - algo contraditório, pois já dissera que sua compreensão era invertida:

O VELHO - Sim. Eu explico. Se alguém lhe diz, por exemplo, que está a chover, ela percebe que está sol. Se lhe dizem que a vida está mais barata, ela entende que está mais cara. E assim por diante. Compreende agora? Por isso, se ela ouviu que eu ia dizer tudo, foi porque eu disse que não ia dizer nada. Nada mais simples, como vê! O PROCURADOR (esforçando-se para entender) - Quer dizer, se ela disse que o senhor disse foi porque o senhor não disse...

O VELHO - Exactamente! E se tivesse dito que eu não tinha dito é porque tinha dito. Estamos entendidos. (REBELLO, 1999, p. 393)

Depois de outros diálogos que deixam claro que A Velha estava dizendo a verdade, o Procurador se dispõe a ouvi-la. A Velha, então, diz tudo: que chovia muito lá dentro, que o teto e a parede estavam caindo de podres, que as janelas não tinham vidros.

O Procurador, explodindo de fúria, os chama de traidores, vendidos, inimigos da ordem, bolchevistas, sabotadores, terroristas. O Velho, em réplicas distintas, quase em delírio, balbucia: “almirante, general, acadêmico, um filho morto pela pátria...”, numa tentativa desalentada de mostrar sua identidade ao Procurador.

O Procurador, sempre com longas falas, argumenta que tudo de melhor lhes fora oferecido e que a ingratidão do casal lhe soa como algo imperdoável, e diz que Sua Excelência, que em breve estaria ali, não merecia tamanha desonra. Os dois GuardaCostas, que até então apenas repetiam em tom de concordância poucas palavras, sentenciam:

$1^{\circ}$. GUARDA-COSTAS (incontidamente) - Morte, morte aos traidores!

$2^{\circ}$. GUARDA-COSTAS (mesmo jogo) - Morte aos traidores!

$[\ldots]$ 


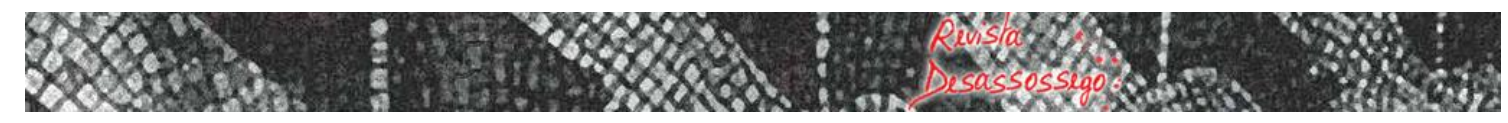

OS DOIS GUARDA-COSTAS - Viva Sua Excelência! (Ao mesmo tempo que disparam as metralhadoras sobre os dois Velhos, que, atônitos, caem por terra.) (REBELLO, 1999, p. 398)

O Procurador, satisfeito, diz aos guardas que não se esquecerá dos dois no próximo relatório, o qual lhes renderá certamente uma promoção. Em seguida, surge uma preocupação: onde esconderiam aquele "lixo", pois a hora da chegada de Sua Excelência se aproximava:

O PROCURADOR - No armário, evidentemente. É para isso que ele aí está. Mas depressa! (Os dois Guarda-Costas aproximam-se dos corpos inanimados dos velhos, preparam-se para arrastá-los em direcção ao armário, quando começam a ouvir-se fora de cena charamelas e vivas) Demasiado tarde. Sua Excelência aproxima-se. (Os Guarda-Costas deixam cair os corpos, correm ao patamar.) (REBELLO, 1999, p. 397)

Os dois Guarda-Costas, em réplicas alternadas, contam regressivamente os degraus subidos por Sua Excelência que, para a surpresa do leitor/ espectador, é "um velho caquético, de aspecto vulpino e maneiras untuosas, a voz trêmula. Veste sobrecasaca e botas de atacar" (Rebello, 1999, p. 397).

Todos no ambiente o saúdam com vivas e aplausos. Mas Sua Excelência quer saber onde estão os inquilinos daquele andar. E pergunta se eles não tinham sido prevenidos de sua visita pelo chefe dos serviços de propaganda, cuja negligência, se assim fosse, seria imperdoável. O Procurador diz que estão mortos:

O PROCURADOR (De repente: as palavras saem-lhe em tropel, numa ânsia visível de afastar a ira de Sua Excelência) - De emoção, Excelência!... De pura, inefável, irresistível emoção! Ao receberem a notícia... Ao ser-lhes comunicado que Vossa Excelência, na sua infinita bondade, na sua generosidade sem limites, se dignava, condescendia em visitá-los na sua humilde, mas honrada casa... Matou-os de emoção! A alegria de verem, de ouvirem, de falarem com Vossa Excelência! Foi mais forte do que eles. Não puderam resistir. Parece-me que ainda tenho nos ouvidos as suas últimas palavras, antes de sucumbirem: (Com solene emoção.) Viva Sua Excelência! (REBELLO, 1999, p. 398)

Sua Excelência ordena ao Procurador que os condecore por serviços especiais prestados à "Nossa Nobre Causa". Em seguida, lembra-se de perguntar se o casal havia pagado a renda. Quando o Procurador diz que não houve tempo, 


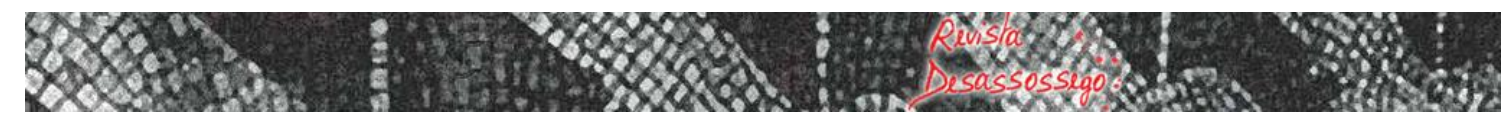

SUA EXCELÊNCIA - Eu logo vi. Súcia de caloteiros! Preferem morrer a pagar a renda. E eu a sacrificar-me por eles, a passar noites em claro, a dar cabo da saúde... (REBELLO, 1999, p. 399)

Sua Excelência chuta os mortos, chama-os de lixo e ordena que seus nomes sejam banidos da lista histórica dos inquilinos e reitera o rigor que é preciso ter com os novos inquilinos: absoluta fidelidade e devoção à "Causa". Tudo deveria ser apresentado à Sua Excelência: antecedentes fisiológicos, psicológicos, patológicos, ideológicos e, para completar, uma radiografia do subconsciente. E ordena aos GuardaCostas que fixem esta máxima: "Só é digno de casa quem for digno da Causa".

A peça termina com uma longa fala de Sua Excelência, hiperbolizando a Causa e, beirando à loucura, num fim apocalíptico, toda a pompa ilusória dela e do prédio desabam.

Sua Excelência empolgadíssima com seu discurso, não percebe que uma tempestade fortíssima toma proporções assustadoras. Barulho de ambulância, de carros de bombeiros, gritos de socorro, nada é percebido pelo líder. Os Guarda-Costas hesitam um pouco, mas fogem. O Procurador resiste um pouco mais, mas quando o armário cai e se abre, mostrando os dois corpos, e quando as paredes desabam, ele também foge, restando apenas Sua Excelência, que só pára com seu discurso após o telhado cair-lhe sobre a cabeça e derrubá-lo ao chão. Furioso, muda então o tom e a linguagem, mas não o discurso: "Filhos da puta, sacanas, ficaram-me a dever um mês de renda!" (Rebello, 1999, p. 401)

\section{A forma da saudade no diálogo dramático}

Peter Szondi, teórico húngaro que muito refletiu acerca do drama moderno, a fim de mostrar as novas formas dramáticas advindas da crise das relações intersubjetivas do final do século XIX, postula que um dos pilares da forma dramática clássica era o diálogo por ser o promotor de ação dramática, altamente investido de valor e muito próprio para precipitar eventos num drama.

O teórico apresenta dramaturgos modernos que tiraram do diálogo essa função e que propuseram novas formas para o drama. Cita, por exemplo, os dramas sem ação, os dramas com diálogos absurdos que não são os responsáveis pelas poucas ações que se sucedem, os dramas cujos diálogos se concentram em rememorações e não conduzem a 


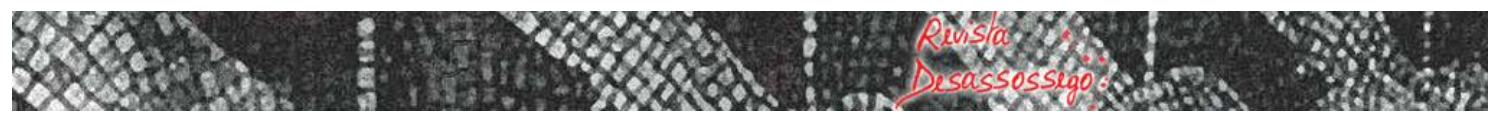

ação no presente, uma vez que o conteúdo das réplicas localiza-se exclusivamente no passado, não tendo muitas vezes relação alguma com o local e com as ações das personagens em cena.

No começo do século XX, as Três irmãs (1901), de Tchékov, o drama estático de Fernando Pessoa, O Marinheiro (1913), e várias outras peças desafiaram uma convenção dramática que ainda valorizava a ação e o enredo.

A causa para o desgaste formal seria a transformação temática em oposição à fixidez da forma dramática, cujo contorno era dado, até o século XIX, por três elementos: pelo fato essencial, pelo presente absoluto e pelas relações intersubjetivas. Szondi exemplifica o conflito em que esta tríade conceitual entrou com as dramaturgias de Ibsen, Tchekhov, Strindberg e Maeterterlinck:

Em Ibsen, o passado domina no lugar do presente. Não é temático um acontecimento passado, mas o próprio passado, na medida em que é lembrado e continua a repercutir no íntimo. Desse modo, o elemento intersubjetivo é substituído pelo intrasubjetivo. Nos dramas de Tchekhov, a vida ativa no presente cede à vida onírica na lembrança e na utopia. $\mathrm{O}$ fato torna-se acessório, e o diálogo, a forma de expressão intersubjetiva, converte-se em receptáculo de reflexões monológicas. Nas obras de Strindberg, o intersubjetivo ou é suprimido ou é visto através da lente subjetiva de um eu central. Com essa interiorização, o tempo presente e "real" perde o seu domínio exclusivo: passado e presente desembocam um no outro, o presente externo provoca $\mathrm{o}$ passado recordado. Na esfera intersubjetiva, o fato restringe-se a uma seqüência de encontros, meras balizas do verdadeiro fato: transformação interna. $\mathrm{O}$ drame statique de Maeterlinck dispensa a ação. Em face da morte, à qual ele se dedicou exclusivamente, desaparecem também as diferenças intersubjetivas e, assim, a confrontação entre homem e homem. (Szondi, 2001, p. 91-2)

Esses são alguns tratamentos que o diálogo dramático recebeu no século $\mathrm{XX}$ e que levaram Szondi a concluir que - como um dos suportes da forma dramática - o diálogo perdera a sua principal função: promover as relações intersubjetivas entre as personagens, a fim de desencadear ações pertinentes ao conteúdo apresentado pelas réplicas e também pelos outros elementos da cena. Ao mesmo tempo em que assumia outras funções: ser receptáculo de reflexões monológicas, como em Tchekov; ser meras balizas do verdadeiro fato, em Strindberg; e, ainda, ser intrassubjetivo, como em Ibsen, em cujo teatro o passado é sempre dominante. 


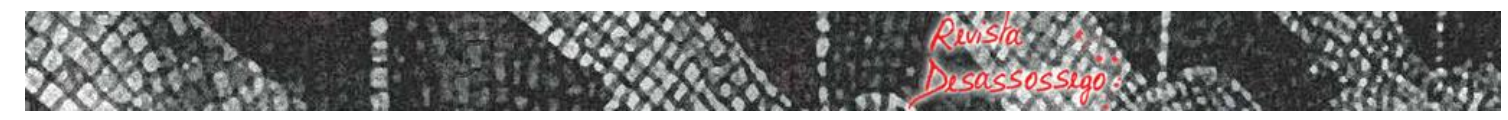

Em A Visita de Sua Excelência os diálogos que relembram o passado funcionam como espécie de acostamentos que contornam a ação central, conclui-se que a maior parte dos diálogos nessa peça não são unidades de oposição que almejam uma superação, como costuma ocorrer com o diálogo clássico. São falas que são ditas para que as personagens sejam caracterizadas internamente, para que a saudade tome forma e força a ponto de agudizar a oposição entre o passado bom, este sim digno de memória e saudade, e o presente de infortúnio.

Em outros momentos, as personagens dialogam entre si, mas não ouvem ou respondem conforme a lógica do conteúdo expresso pelo interlocutor. Mimetizam ou uma situação de desinteresse pelo outro ou uma situação de introjeção absoluta. Parece que os diálogos funcionam simplesmente como uma legenda para que o interior das personagens e o sentimento de angústia e saudade que as persegue sejam explicitados.

O tema da saudade, do apego ao passado, do desejo de reviver os bons tempos de outrora é expresso na cultura literária portuguesa sob diversas formas. Especialmente nesta peça, Rebello parece elaborar formalmente o tema da saudade reconhecendo na incomunicabilidade ou na incapacidade dos diálogos precipitarem ações neste drama, uma vez que não há como recobrar o tempo perdido, não há ação capaz de devolver o tempo bom que existiu um dia.

Em A Visita de Sua Excelência, o diálogo, genuinamente dramático, só aparece no momento em que surgem as personagens que estabelecem uma relação positiva com o presente: os responsáveis pela transformação do passado bom do casal num presente de sofrimento. Os diálogos comprometidos com a condução da ação são proferidos pelos guardas, por Sua Excelência. Estes, sim, situados no presente, precipitam ações e conduzem o casal às últimas conseqüências: a morte.

Desse modo, os diálogos de A Visita de Sua Excelência, assim como de muitas outras peças de Rebello, não têm um mesmo valor dramático: uns conduzem à ação; outros, não. Os que não conduzem a uma transformação presentificam o passado por meio da lembrança das personagens. Já os que conduzem, mostram que o presente é tão passageiro como foi o passado.

A ironia retórica, como linguagem discursiva, e a alegoria, como forma dramática, garantem uma possibilidade, ainda que indireta, de discussão da situação política de Portugal - discussão que não poderia ser feita, naquele momento, com 
diálogos, caracterizações e ambientações desprovidos de artifícios. A estratégia cênica usada por Rebello, na qual a alegorização assume um espaço que permite intensificar a ironia por desrealizar a cena por completo, é o que confere atemporalidade à peça e a livra, com tranqüilidade, de ser uma obra datada.

Superando essa dificuldade contingente, Rebello consolida uma linguagem cênica que já tinha experimentado em $O$ mundo começou às 5 e 47, peça marco da moderna dramaturgia portuguesa, e que no seu teatro se iria aprimorando, nas décadas seguintes, revestindo-se de diversas formas ao tornar concreto algo abstrato por meio de outros universos compostos por figuras de linguagens, montagens, intertextos, elementos fantásticos etc.

\section{Bibliografia}

REBELLO, Luiz Francisco. A visita de Sua Excelência. In: Todo o teatro. Lisboa: Imprensa Nacional - Casa da Moeda, 1999, 381-401.

SZONDI, Peter. Teoria do drama moderno [1880 - 1950]. São Paulo: Cosac \& Naify, 2001. 